\title{
MJN KNOWLEDGE, ATTITUDE, AND PRACTICE TOWARDS BLOOD DONATION AMONG UNDERGRADUATE STUDENTS OF HEALTH CAMPUS, UNIVERSITI SAINS MALAYSIA
}

\author{
Nursyafiqah Izzati Zainal Abidin, Duangta Shet* \\ Program of Nursing, School of Health Sciences, Universiti Sains Malaysia, Malaysia \\ *Corresponding Author's Email: duangta@usm.my
}

\begin{abstract}
Blood donation is crucial to save millions of people, especially patients suffering from various health-related illnesses and issues. It is essential to create awareness among the society at large and students about blood donation to sustain a consistent blood supply. The aim of the study is to assess knowledge, attitude, and practice towards blood donation among undergraduate students of the Health Campus, USM. Methods: A descriptive cross-sectional design using self-administered questionnaires was conducted among undergraduate students of the Health Campus, USM. A total of 94 students was selected using a purposive sampling technique that were included in the study sample from a total 124 students. Results: Among 94 undergraduate students, $97.9 \%$ and $96.8 \%$ had adequate knowledge and positive attitudes towards blood donation, respectively. From the total number of selected students, only $40.4 \%$ of them had never donated blood before. Conclusion: Although most of the students had adequate knowledge and positive attitudes towards blood donation, blood donation practice was still low. Recommendations: Targeted approaches should be designed to increase awareness of health science students about the importance of blood donation. Strategies that encourage and motivate the students should also be developed.
\end{abstract}

Keywords: Knowledge; Attitude; Practice; Blood Donation

\section{INTRODUCTION}

Blood is the most precious gift that anyone can give to another person. It is a gift, a lifesaver for millions of people, but it is also a scarce product (Gebresilase et al., 2017). People of all ages around the world, especially patients with bleeding disorders, accidents, surgeries, inherited diseases, malignancies, and many other healthrelated illnesses and issues, need blood transfusions to survive. Blood transfusion is the donation of blood or blood products from the donor into the bloodstream of the recipient (Melku et al., 2018; Melku, Terefe \& Asrie, 2016). It is a life-saving scheme in both routine and emergencies to replace blood cells or blood products lost. Millions of blood units are collected from donors every year, but demands are increasing day by day that is increasing the demand for sufficient and timely provision of blood (Ahmed et al., 2014).

According to World Health Organization (2017), there are 112.5 million blood donations recorded globally in which approximately half of which are collected in high-income countries comprising only $19 \%$ of the human population around the world. In Malaysia, blood donation is centered on voluntary non-remunerated sources (Ling et al., 2018). On this basis, the total number of blood donations from mobile sites, blood collection centers, and hospitals increased by $3.4 \%$ from 653,124 to 675,315 cases between 2013-2014. However, despite the increase in the number of blood donors in Malaysia, there is still a severe shortage of blood with decreasing donor population and increasing demand (Seong et al., 2014). In fact, the blood donation rate in Malaysia is still low, as only $2.2 \%$ of the entire population are donors compared to $3.5-5.0 \%$ recorded in developed countries in 2014 (Bernama, 2015). While the World Health Organization (2016) stated that blood donation rates are 33.1, 11.7, and 4.6 donations per 1000 people for high, middle and low-income countries respectively, the current Malaysian scenario translates to only 22.5 donations per 1000 people (Ling et al., 2018). This 
suggests that much needs be done to improve the donation rates in Malaysia.

Given the blood scarcity situation, blood banks and blood transfusion centers are obliged to organize more frequent blood donation programs to maintain a regular blood supply and to adopt an approach for increasing new blood donor recruitment and retention of donor. One of the requirements of World Health Organization in its basic approach to encourage global safety and minimize risks related with blood transfusion is that the blood should be collected only from voluntary donors (Ling et al., 2018). The healthy, active, and receptive young people are potential blood donors to meet safe blood requirements. Part of the young people is Health Science university students who are healthy, active, and responsive, may constitute a more significant part of blood donation. These young people need to continually be encouraged, inspired, and motivated to donate blood voluntarily. If applicable approaches are implemented to improve knowledge, attitude, and practice towards blood donation, these young people may become not only the potential blood donor but also the motivator and a role model to the society. Thus, this study aims to assess the knowledge, attitude, and practice towards blood donation among the final year undergraduate School of Health Sciences students in USM's Health campus.

\section{METHODOLOGY}

A descriptive cross-sectional design was used in this study. The quantitative approach was adopted to collect, analyze, and interpret numerical data focusing on relations among a smaller number of attributes across many cases. This approach is based on the paradigm of philosophy that can be observed, measured, and can eventually be explained. In this study, the quantitative approach was used to obtain sociodemographic information and to get the information on the level of knowledge, attitude, and practice towards blood donation among undergraduate School of Health Sciences students of the Health Campus, USM.

The researchers were needed to select only a few items from the total population for study purposes because a study based on a representative sample is often better than one based on the larger sample or on the whole population since there is no need interviewing a large number of people saying the same thing (Miller,1991). For this study, the selection of the sample is influenced by factors such as the size of the population and the specific population parameters of interest and purposive sampling was done to select the sample size. A total of 94 students was selected for the study sample out of the total 124 students from five different courses (Audiology, Dietetic, Medical Radiation, Nutrition, and Speech Pathology) from the Health Campus, USM. Raosoft calculator was used to calculate the sample size in this study for an infinite population using $95 \%$ confidence level, $5 \%$ margin of error with anticipation of $50 \%$ response distribution.

A structured questionnaire was required to be filled by the students. The questionnaire consists of four main sections. Section one was designed to measure sociodemographic data such as gender, course, and ethnicity. Section two, three and four were about the knowledge regarding blood donation, the attitudes towards blood donation, and the practices towards blood donation, respectively.

Permission from the Ethics Committee and Dean of the School of Health Science was obtained prior to data collection. Appointments with final year undergraduate School of Health Sciences students from USM's Health Campus were arranged on a fixed date. The researcher explained the nature and purpose of the study to all selected students. Those who agreed to participate in this study had given informed consent. A total of 94 undergraduate School of Health Sciences students were interviewed by the researcher using self-administered questionnaires to gain necessary information like gender, course and ethnicity. Information regarding knowledge, attitude and practice of blood donation were also obtained through the same questionnaire. In order to make it easy for students to answer and contribute to this study, the researcher designed the questionnaire that was not too long and took too much time to be completed. Upon completion, the researcher collected the survey questionnaires. A small token of appreciation was given to the participants.

The process of analyzing the data contained in the questionnaire begins with the preparation of the completed questionnaires. Questionnaires that have been completed was encoded and entered in the Statistical Package for Social Science (SPSS, Version 24) for analysis. Descriptive statistics such as frequency (f) and percentage (\%) was used to determine the level of knowledge, attitude and practice towards blood donation. Meanwhile, the Pearson's Chi-Square test was carried out to analyze the perceived relationship between sociodemographic characteristics (gender, course, and 
ethnicity) with knowledge, attitude and practice towards blood donation among final year undergraduate School of Health Sciences students in USM's Health Campus. The significance level was set at $p$-value $\leq 0.05$ for all statistical analysis. At the 5\% level of significance, the null hypothesis is rejected if the p-value is lower than 0.05 .

\section{RESULTS}

\section{Sociodemographic Characteristics}

A total of 94 out of 124 final years undergraduate School of Health Sciences students in USM's Health Campus agreed to participate in this study. The majority of the participants were female $(93.6 \%)$. The highest number of participants that participated in this study were from the Nutrition course $(26.6 \%)$. Most of the participants are Malay (86.2\%). The complete list of sociodemographic characteristics of the study participants is presented in Table 1 .

Table 1: Sociodemographic Characteristics of the Study Participants

\begin{tabular}{|l|c|}
\hline Variables & n (\%) \\
\hline Gender & $6(6.4)$ \\
Male & $88(93.6)$ \\
Female & \\
\hline Course & $23(24.5)$ \\
Dietetic & $25(26.5)$ \\
Nutrition & $11(11.7)$ \\
Audiology & $11(11.7)$ \\
Speech Pathology & $24(25.5)$ \\
Medical Radiation & $81(86.2)$ \\
\hline Ethnicity & $8(8.5)$ \\
Malay & $1(1.1)$ \\
Chinese & $4(4.3)$ \\
Indian & \\
Others & \\
\hline
\end{tabular}

\section{Level of Knowledge Towards Blood Donation}

Table 2 shows the knowledge towards blood donation among the final year undergraduate School of Health Sciences students at USM's Health Campus. All the participants were asked to assess their knowledge about various aspects of blood donation and blood transfusion. Based on the score, the majority of the participants had good knowledge regarding most of the aspects of blood donation and blood transfusion $(50 \%$ and above). However, less than $50 \%$ of the participants know the amount of blood drawn for each donation, the number of times a person can donate blood in a year, and the blood group that can be received by all patients who need a blood transfusion.

Table 2: Knowledge Towards Blood Donation Among Final Year Undergraduate School of Health Sciences Students in Usm's Health Campus

\begin{tabular}{|l|c|c|}
\hline Response & $\begin{array}{c}\text { Correct answer } \\
\mathbf{n}(\%)\end{array}$ & $\begin{array}{c}\text { Incorrect } \\
\text { answer } \\
\mathbf{n}(\%)\end{array}$ \\
\hline $\begin{array}{l}\text { Amount of blood drawn for each } \\
\text { donation. }\end{array}$ & $48(51.1)$ & $46(48.9)$ \\
\hline $\begin{array}{l}\text { Correct age range for blood donation } \\
\text { in Malaysia. }\end{array}$ & $30(31.9)$ & $64(68.1)$ \\
\hline Minimum weight of donor. & $60(63.8)$ & $34(36.2)$ \\
\hline $\begin{array}{l}\text { Duration of donated red blood cells } \\
\text { replacement in donor. }\end{array}$ & $65(69.1)$ & $29(30.9)$ \\
\hline $\begin{array}{l}\text { How many times can a person } \\
\text { donate blood in a year? }\end{array}$ & $31(33.0)$ & $63(67.0)$ \\
\hline $\begin{array}{l}\text { Donated blood is screened for AIDS, } \\
\text { Hepatitis B and C before } \\
\text { transfusion. }\end{array}$ & $89(94.7)$ & $5(5.3)$ \\
\hline Can pregnant women donate blood? & $25(26.6)$ & $69(73.4)$ \\
\hline $\begin{array}{l}\text { Which blood group can be received } \\
\text { by all patients who need blood } \\
\text { transfusion? }\end{array}$ & $78(83.0)$ & $16(17.0)$ \\
\hline $\begin{array}{l}\text { Can a woman donate blood during } \\
\text { her period? }\end{array}$ & $92(97.9)$ & $2(2.1)$ \\
\hline $\begin{array}{l}\text { A potential donor should have a } \\
\text { stable vital sign (blood } \\
\text { pressure/temperature/pulse and } \\
\text { respiratory rates) before donate } \\
\text { blood. }\end{array}$ & & $8.5)$ \\
\hline
\end{tabular}

\section{Level of Attitude Towards Blood Donation}

In terms of attitude towards blood donation, the majority of the participants showed a better level of attitude towards blood donation. All of the participants agreed that blood donation is a good habit. Most of the participants $(96.8 \%)$ were willing to donate blood to anyone, especially in cases of emergency. However, there are $(10.6 \%)$ participants only willing to make a blood donation if they are paid for it. The detailed description of the attitude towards blood donation among final year undergraduate School of Health Sciences students in USM's Health Campus is presented in Table 3.

\section{Table 3: Attitude Towards Blood Donation}

\begin{tabular}{|l|c|c|}
\hline Response & Yes n (\%) & No n (\%) \\
\hline Blood donation is a good habit. & $94(100.0)$ & $0(0.00)$ \\
\hline $\begin{array}{l}\text { I am interested to donate blood } \\
\text { only to the person that I know. }\end{array}$ & $15(16.0)$ & $79(84.0)$ \\
\hline $\begin{array}{l}\text { I want to donate blood only if I get } \\
\text { paid for it. }\end{array}$ & $10(10.6)$ & $84(89.4)$ \\
\hline $\begin{array}{l}\text { I am willing to donate blood to } \\
\text { anyone especially in case of } \\
\text { emergency. }\end{array}$ & $91(96.8)$ & $3(3.2)$ \\
\hline
\end{tabular}

\section{Level of Practice Towards Blood Donation}

Relating to blood donation practices, $40.4 \%$ of 
undergraduate School of Health Sciences students in USM's Health Campus donated blood at least once in their lifetime. Out of the total number (40.4\%), only $8.5 \%$ of the participants donated blood at least once in a year. The majority of the participants agreed that blood donation was not just for acquaintances or family members only, and the practice towards blood donation should not be for money or rewards. Further details of practice towards blood donation among final year undergraduate School of Health Sciences students in USM's Health Campus is illustrated in Table 4.

Table 4: Level of Practices towards Blood Donation

\begin{tabular}{|l|c|c|}
\hline Response & & n (\%) \\
\hline Have you ever donated blood? & & \\
Yes & & $38(40.4)$ \\
No & & $56(59.6)$ \\
\hline If yes, please specify: & & $8(8.5)$ \\
Once a year & & $6(6.4)$ \\
Twice a year & & $3(3.2)$ \\
Every 3 months & Yes n (\%) & No n (\%) \\
Not regular & $68(72.3)$ & $26(27.7)$ \\
\hline & $4(4.3)$ & $90(95.7)$ \\
\hline I donated blood voluntarily & $4(4.3)$ & $90(95.7)$ \\
\hline I donated blood only for my relatives or & & \\
friends & &
\end{tabular}

\section{DISCUSSION}

Sustaining the demand for blood supply is the main apprehension, especially for health-related organizations. Hence, identifying the level of knowledge, attitude, and practice towards blood donation is very important. In this study, an effort was made to identify the knowledge, attitudes, and practices towards blood donation among final year undergraduate School of Health Sciences students from USM's Health Campus.

\section{Level of Attitude towards Blood Donation}

The finding of this study revealed that $(95.7 \%)$ of undergraduate final year School of Health Sciences students from USM's Health Campus have good knowledge about blood donation. This percentage is higher when compared with the study conducted on students of Addis Ababa University Health Science, which was (83.6\%) (Misganaw et al., 2014). This is also higher than the study conducted on Health Science students of Arsi University and Non-Health Science students of Adama Science and Technology University (79.4\%) (Gebresilase et al., 2017). The possible reason for the good knowledge of blood donation might be related to the background of the participants who are Health Science students that are more exposed to the study of saving a human life. The finding of this study is consistent with those of Sabu et al., (2011). They revealed that Health Science students are more educated and literate about the importance of saving human lives and it is expected that they should be more knowledgeable on blood donation compared to illiterates and uneducated strata of the population.

\section{Level of Attitude Towards Blood Donation}

This study also revealed that the majority of the participants had positive attitudes towards blood donation (96.8\%). This is comparable to a study conducted in South India in which (83.7\%) of the participants showed favorable attitudes (Sabu et al., 2011). A significantly good level of attitude of the participants towards blood donation might be due to the effect of the education delivered to them. The direct exposure to the hospital environment might improve the knowledge and attitudes of the students. The same views are also highlighted by Gebresilase et al. (2017) in a study on knowledge, attitudes, and practices of students towards blood donation in Arsi University and Adama Science Technology University.

\section{Level of practice towards blood donation}

This study also found that $40.4 \%$ of the participants had donated blood at least once in their lifetime. This is higher compared to a study conducted in South India, in which $10.7 \%$ of the study's participants had donated blood (Manikandan et al., 2013). However, the percentage of blood donation practices among the participants in this study was slightly lower compared to a study conducted in Canada that showed $43.8 \%$ of the study participants had donated blood at least once in their lifetime (Lemmens et al., 2008). Based on the difference in percentage between the level of knowledge and the level of practices towards blood donation, this study found that the level of knowledge has no significant association with the level of practices towards blood donation among the final year undergraduate School of Health Sciences students from USM's Health campus. This is similar to several previous studies (Gebresilase et al., 2017; BhaRatWaj et al., 2012; Sabu et al., 2011). The percentage of blood donation practices in this study could be attributed to the lack of opportunity and requests for blood donation by donor recruitment programs. Gebresilase et al., (2017) suggested that to increase the number of volunteer blood donors, and students need to be encouraged to donate blood through different blood campaigns.

\section{CONCLUSION}

In conclusion, this study found that the majority of the 
participants in this study had adequate knowledge and positive attitudes towards blood donation. However, the practice of blood donation among the study participants is still low. This situation shows that being knowledgeable about blood donation did not necessarily transform into better practice. Steps to increase awareness concerning blood donation should be applied to these young people as one of the strategies to improve the blood donation rate in the future. Educational courses and blood donation programs are needed to motivate and encourage university students towards voluntary blood donation. Different models should be developed, piloted and tested in the educational programs, and students should be encouraged to donate blood voluntarily and regularly to achieve the World Health Organization goal of $100 \%$ voluntary nonremunerated blood donation by 2020 .

\section{Conflict of Interests}

The authors declare that they have no conflict of interest.

\section{ACKNOWLEDGEMENTS}

The authors are thankful to the institutional authority for completion of the work.

\section{REFERENCES}

Ahmed, Z., Zafar, M., Khan, A.A., Anjum, M.U. \& Siddique, M.A. (2014). Knowledge, Attitude, and Practices about Blood Donation among Undergraduate Medical Students in Karachi. Infectious Diseases \& Therapy, 2(2), pp 2-4.

Bernama. (2015). Subramaniam: Only 2.2\% of Malaysian population donate blood. The Sun Daily, 14 June 2015.

BhaRajWat, R., Vijaya, K. \& RajaRam, P. (2012). A Descriptive Study of Knowledge, Attitude and Practice with regard to Voluntary Blood Donation among Medica Undergraduate Students in Pondicherry, India. Journal of Clinical and Diagnostic Research, 6(4), pp 602-604.

Gebresilase, H.W., Fite, R.O. \& Abeya, S. G. (2017). Knowledge, attitude, and practice of students towards blood donation in Arsi Univeristy and Adama Science and Technology Univesity: a comparative cross sectional study. BMC Hematology, pp 2-10.

Lemmens, K., Abrham, C., Ruiter, R., Veldhuizen, I., Bos, A. \& Schaalma, H. (2008). Identifying blood donors willing to help with recruitment. Vox Sang, 95(3), 211-217.

Ling, L.M., Tan, A.G., Hui, T. S. \& Ling, G. S. (2018). Determinations of Blood Donation Status in Malaysia: Profiling the Non-Donors, Ocassional Donors and Regular Donors. Kajian Malaysia, 36, pp 43-62.

Manikandan, S., Srikumar, R. \& Ruvanthika, P. (2013). A study on KAP on blood donation among health profession student in Chennai, Tamil's ado, South India. International of scientific and research publication, 3(3), pp 2-4.

Melku, M., Asrie, F., Shiferaw, E., Woldu, B., Yihunew, Y., Asmelash, D. \& Enawgaw, B. (2018). Knowledge, Attitude and Practice Regarding Blood Donation among Graduating Undergraduate Health Science Students at the University of Gondor, Northwest Ethiopia. Ethiopian Journal of Health Sciences., 28(5), pp 517-582.

Melku, M., Terefe, B. \& Asrie, F. (2016). Knowledge, Attitude and Practice of Adult Population towards Blood Donation in Gondar Town, Northwest Ethiopia: A Community Based Cross-Sectional Study. Journal of Blood Transfusion, pp 7986.

Miller, D. (2012). Research Design and Social Measurement. Newburry Park, California: SAGE Publication.

Misganaw, C., Tenkir, M., Deresa , A., Tesfaye, M., Tessema, T. \& Taye, H. (2014). The level and associated factors of knowledge, attitude and practice of blood donation among health science students of Addis Ababa University. IJMHSR, $10,105-118$

Sabu, K.M., Remya, A., Binu, V.S. and Vivek, R. (2011). Knowledge, attitude and practice on blood donation among health science students in a university campus, South India. Online Journal of Health and Allied Sciences, 10(2), pp 1-3.

Seong, W., Raffeal , V. \& Ayob, Y. (2014). Adopting a proactive approach to blood shortages: Experience from the national blood centre, Malaysia. ISBT Science Series, 9(1), 189-192.

World Health Organization (2016). Blood safety and availability. Retrieved from Factsheet. Geneva: World Health Organization. Retrieved from: http://www.who.int/mediacentre/factsheet/fs279/en/.

World Health Organization (2017). The 2016 global status report on blood safety and availability. 